\title{
Thrombosis of splenic artery pseudoaneurysm complicating pancreatitis
}

\author{
Th De Ronde, B Van Beers, L de Cannière, J P Trigaux, M Melange
}

\begin{abstract}
The natural history of pseudoaneurysms complicating pancreatitis is unknown. A patient with chronic pancreatitis is described in whom thrombosis of a splenic artery pseudoaneurysm occurred. Early diagnosis and radical treatment of a bleeding pseudoaneurysm are mandatory. When elective treatment is considered, however, contrast enhanced computed tomography may be useful just before surgery as thrombosis may occur.
\end{abstract}

(Gut 1993; 34: 1271-1273)

Departments of GastroEnterology, Th De Ronde M Melange

Radiology,

B Van Beers

J P Trigaux

and General and

Digestive Surgery,

Cliniques Universitaires

UCL de Mont-Godinne

Yvoir, Belgium

$\mathrm{L}$ de Cannière

Correspondence to:

Dr Th De Ronde, Cliniques

Universitaires UCL de Mont-

Godinne, B 5530 Yvoir, Belgium

Accepted for publication 5 January 1993

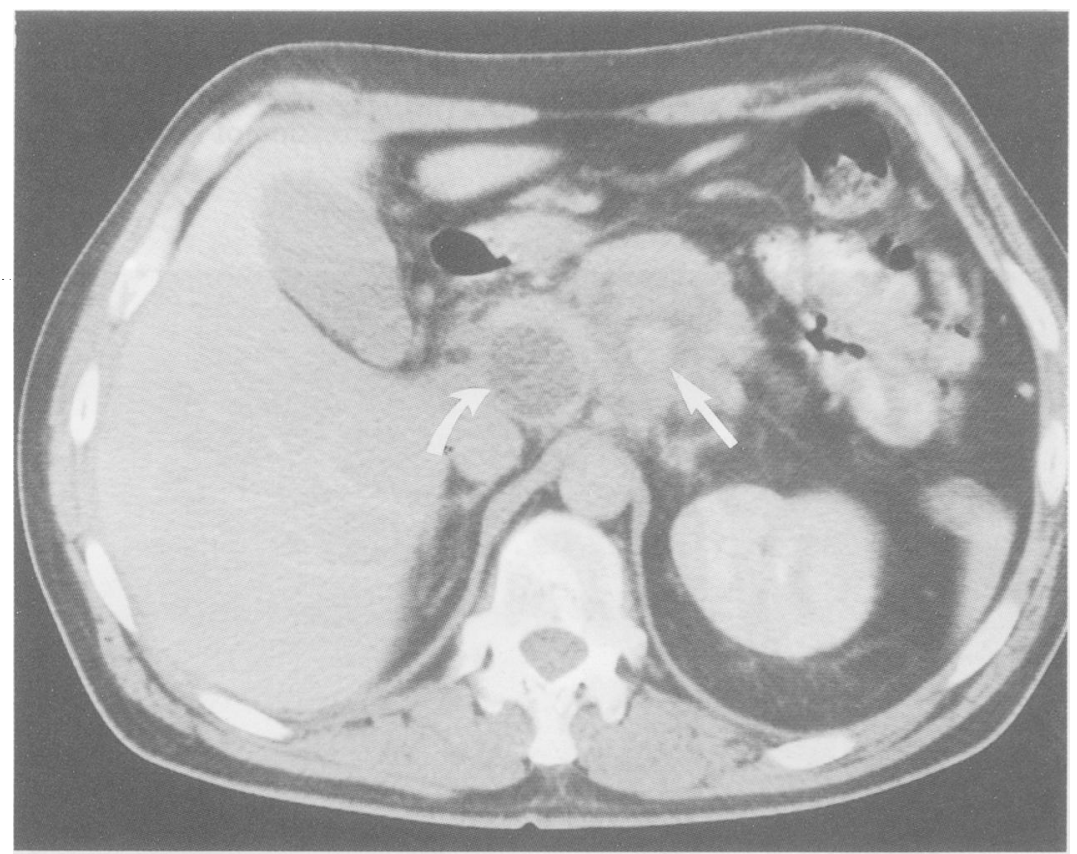

Figure 1: Computed tomography shows an eccentric contrast enhancing lesion, $1.5 \mathrm{~cm}$ in diameter (straight arrow) within a retrocorporeal pseudocyst where density is increased. Another pseudocyst is seen above the pancreatic head (curved arrow). tory syndrome/erythrocyte sedimentation rate: $91 \mathrm{~mm} / \mathrm{h}$ (normal <15), fibrinogen $7 \cdot 44 \mathrm{~g} / 1$ (normal $1 \cdot 80-4 \cdot 00$ ), and $C$ reactive protein 120 $\mathrm{mg} / \mathrm{l}$ (normal $<7$ ); a mild hyperleucocytosis was seen at $12.6 \times 10^{9} / 1$ (normal 4-10). Pancreatic enzymes were of normal values.

A computed tomography examination showed a pseudocyst, $3 \mathrm{~cm}$ in diameter, in the pancreatic head and several pseudocysts located behind the body of the pancreas; a dilatation of the main pancreatic duct was seen in the tail. Endoscopic retrograde pancreatography showed irregular dilatation of the main pancreatic duct in the tail and opacification of three pseudocysts, one in the head and two in the body of the pancreas. The patient stopped any alcohol intake but his pain worsened despite analgesics.

Three weeks later, a second CT examination was performed. It showed an eccentric contrast enhancing mass, $1.5 \mathrm{~cm}$ in diameter, within one of the corporeal pseudocysts in which density was increased (Fig 1).

A coeliac and splenic angiography showed a postostial pseudoaneurysm of the splenic artery without active bleeding (Fig 2). Stable catheterisation of the splenic artery near the ostium was not possible, precluding transcatheter embolisation of the feeding artery. Selective catheterisation of the pseudoaneurysm itself was not attempted because of the risk of rupture. Somatostatin infusion (Somatostatine UCB 250 $\mu \mathrm{g} / \mathrm{h}$ ) was given to reduce pancreatic secretion and elective surgical intervention was decided on for the seventh day.

Computed tomography, performed the day before planned surgery, showed a spontaneous hyperdensity and a lack of contrast enhancement of the pseudoaneurysm, suggesting recent thrombosis (Fig 3). A coeliac angiography confirmed the thrombosis of the pseudoaneurysm and the permeability of the splenic artery (Fig 4).

Computed tomography performed two months and one year later showed regression of the clotted pseudoaneurysm and progressive disappearance of the pseudocysts.

\section{Discussion}

Arterial pseudoaneurysms are not uncommon with acute or, more often, chronic pancreatitis especially when pseudocysts are present. ${ }^{1-}$ Pseudoaneurysms are caused by enzymatic digestion ${ }^{67}$ or local compression of the vessel by the pseudocyst. ${ }^{3}$ Because of its proximity to the pancreas, the splenic artery is the most commonly affected vessel. ${ }^{3+6}$ Visceral pseudoaneurysms are difficult to diagnose. They may be detected with computed tomography and duplex sonography, but selective angiography is still the diagnostic examination of choice. ${ }^{89}$ 


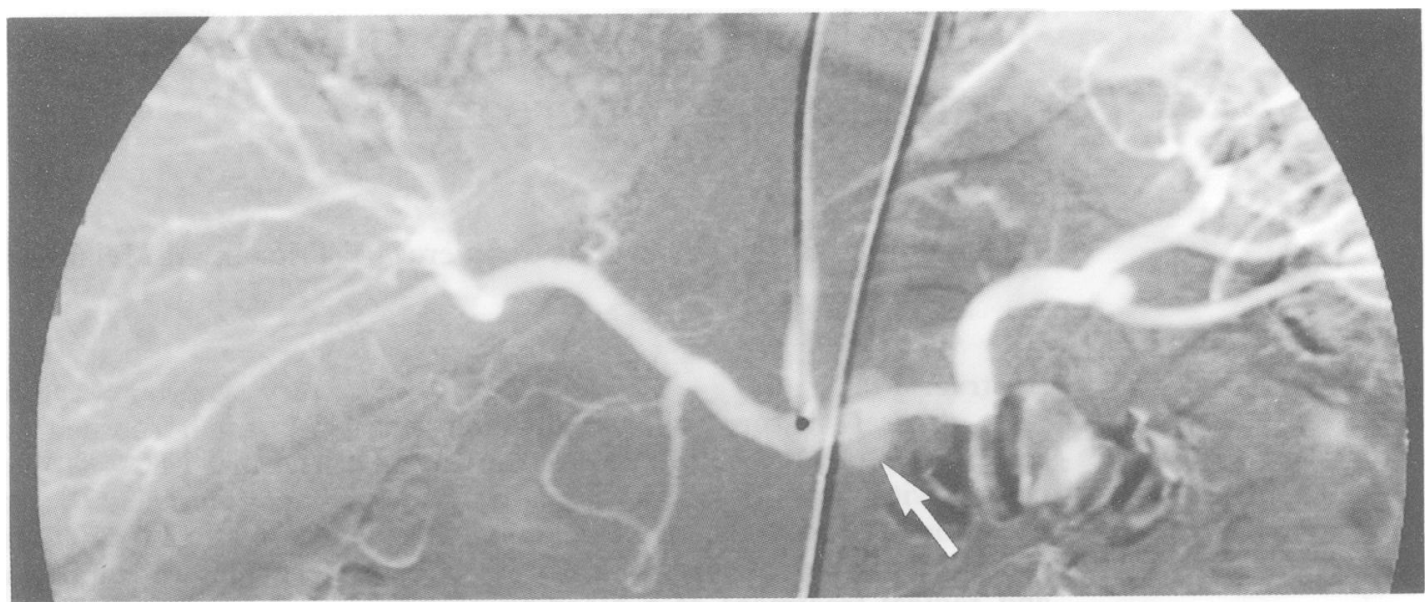

Figure 2: Coeliac arteriogram shows a postostial pseudoaneurysm of the splenic artery (arrow).

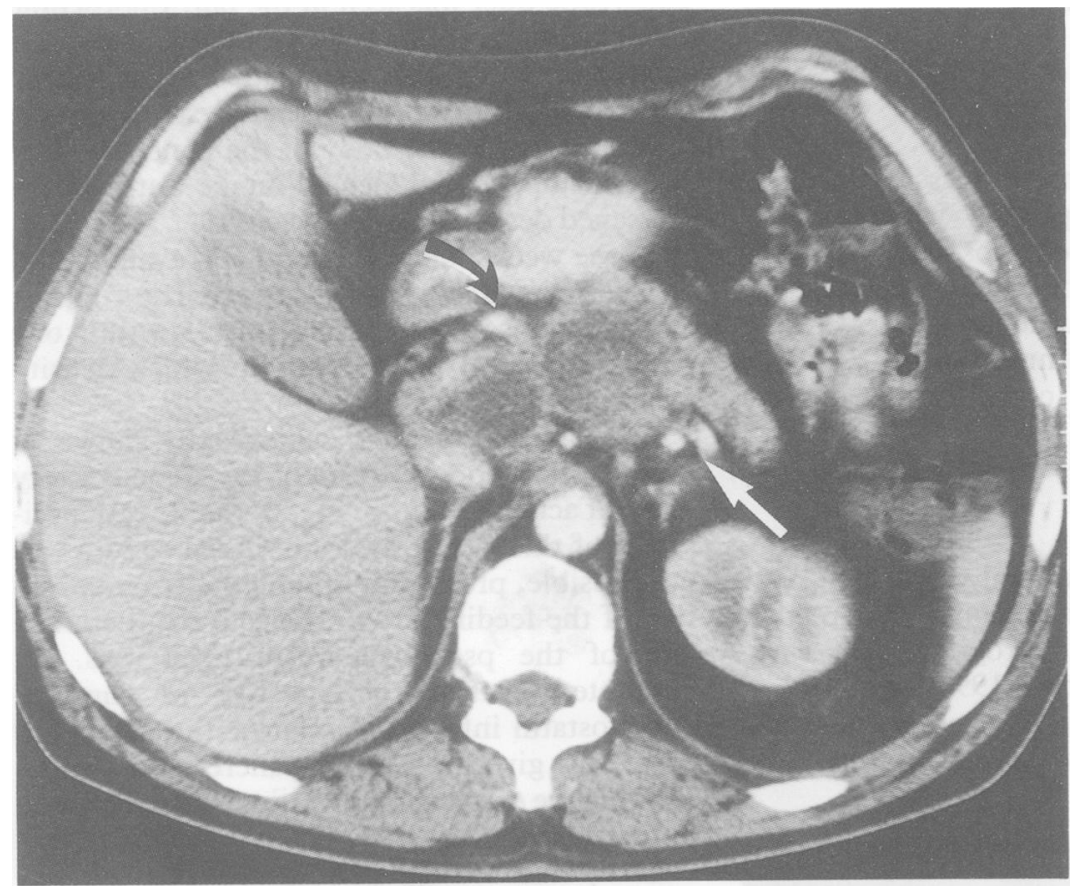

Figure 3: Computed tomography performed nine days later shows a lack of contrast enhancement of the pseudoaneurysm, suggesting thrombosis. Notice the high enhancement of the aorta, the splenic artery (white arrow), and the hepatic artery (black arrow).
- The main risk of visceral pseudoaneurysm is rupture and consecutive bleeding. This risk is much higher in pseudoaneurysms secondary to pancreatitis. ${ }^{1011}$ Bleeding can occur directly or through the pseudocyst, if present. This may cause secondary rupture in the main pancreatic duct, the peritoneum, the retroperitoneum or more often in an adjacent viscus such as duodenum, stomach or transverse colon. ${ }^{1361213}$ Early diagnosis and radical treatment are thus mandatory. Surgery is the classic treatment of pseudoaneurysm but transcatheter arterial embolisation seems to be a very attractive alternative either to permit further elective surgery or as a definitive treatment with good results and a lower mortality than surgery. ${ }^{357}$

The incidence and natural history of pseudoaneurysms complicating chronic pancreatitis is unknown. At angiography performed in patients with chronic pancreatitis without gastrointestinal bleeding pseudoaneurysms have been seen in $10-21 \%$ of cases ${ }^{36714}$ but only $1-8 \%$ of gastrointestinal bleedings in patients with pancreatic pseudocysts are thought to be pseudoaneurysm related. ${ }^{3}$ These data suggest that not all pseudoaneurysms will lead to gastrointestinal haemorrhage. ${ }^{3}$ Spontaneous regression of small visceral

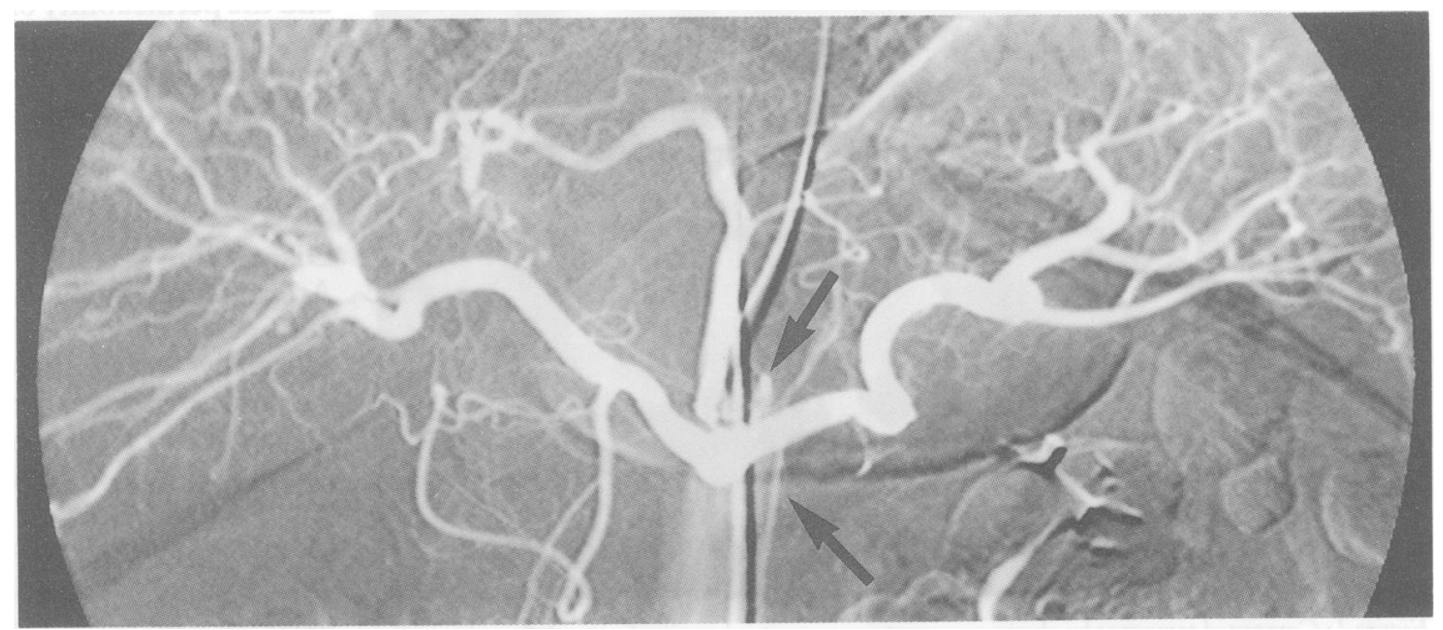

Figure 4: Coeliac arteriogram confirms the lack of enhancement of the clotted pseudoaneurysm. (Arrows point to reflux of contrast material in the aorta.) 
pseudoaneurysms has been reported, including pseudoaneurysms of the splenic artery. ${ }^{15}$ Several authors have thus recommended a conservative approach for asymptomatic patients with visceral pseudoaneurysms smaller than $2.5 \mathrm{~cm}$ in diameter, except for women of child bearing age..$^{1016}$

Spontaneous early thrombosis of pseudoaneurysms secondary to pancreatitis has not been described, however, except in one case affecting the inferior pancreaticoduodenal artery. " Pseudoaneurysms complicating pancreatitis are thought to be the most life threatening of all splanchnic artery aneurysms with death rate greater than $50 \% .^{10}$

We have no clear explanation for the thrombosis of the pseudoaneurysm in our case. It may be related to the catheterisation of the coeliac trunk and the splenic artery. Trauma during catheterisation seems unlikely, however, because the splenic artery remained permeable on follow up studies and catheterisation of the pseudoaneurysm was not performed.

Somatostatin is known to reduce splanchnic blood flow without modifying systemic arterial blood pressure. ${ }^{17}$ The mechanism of action is still debated. ${ }^{18}$ Some authors have suggested that somatostatin may act by a direct vasoconstrictive effect on the splanchnic arterioles or may lower intestinal vasodilating hormones and glucagon. ${ }^{17}$ It has been shown that somatostatin has no effect on haemostasis, and particularly on platelet aggregation, with clinical doses of 250 and 500 $\mu \mathrm{g} / \mathrm{h}$ in non-diabetic subjects; only with a higher dose $(750 \mu \mathrm{g} / \mathrm{h})$ were circulating platelet aggregates detected. ${ }^{19}$ The role of somatostatin, infused at a rate of $250 \mu \mathrm{g} / \mathrm{h}$, in our patient remains thus hypothetical.

In conclusion, early diagnosis and radical treatment of symptomatic peripancreatic pseudoaneurysms are mandatory. When transcatheter embolisation is unsuccessful, however, and in the absence of acute bleeding that requires emergency surgery, a contrast enhanced computed tomography just before elective surgery may be useful as thrombosis may occur. Further investigations about somatostatin in this field could also be of interest.

1 El Hamel A, Parc R, Adda G, Bouteloup PY, Huguet C, Malafosse $M$. Bleeding pseudocysts and pseudoaneurysms in chronic pancreatitis. Br $\mathcal{F}$ Surg 1991; 78: 1059-63.

2 Cahow CE, Gusberg RJ, Gottlieb LJ. Gastrointestinal hemorrhage from pseudoaneurysms in pancreatic pseudo-

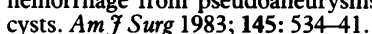

3 Forsmark CE, Wilcox CM, Grendell JH. Endoscopy-negative upper gastrointestinal bleeding in a patient with chronic upper gastrointestinal bleeding in a patient
pancreatitis. Gastroenterology 1992; 102: 320-9.

4 van Rooyen W, van Blankenstein M, Eeftinck Schattenkerk $M$, de Vries JE, Obertop H, Bruining HA, et al. Haemorrhage from the pancreatic duct: a rare form of upper gastrointestinal bleeding. BrF Surg 1984; 71: 137-40.

5 Vujic I. Vascular complication of pancreatitis. Radiol Clin North Am 1989; 27: 81-91.

6 Burke JW, Erickson SJ, Kellum CD, Tegtmeyer CJ, Williamson BRJ, Hansen MF. Pseudoaneurysms complicating pancreatitis: detection by CT. Radiology 1986; 161: 447-50.

7 Mandel SR, Jaques PF, Mauro MA, Sanofsky S. Nonoperative management of peripancreatitic arterial aneurysms. A tive management of peripancreatitic arterial an

8 Kibbler CC, Cohen DL, Cruicshank JK, Kushwaha SS, Marsha y Morgan, Dick RD. Use of CAT scanning in the diagnosis and management of hepatic artery aneurysm. Gut 1985; 26: 752-6.

9 Tobben PJ, Zajko AB, Sumkin JH, Bowen A, Fuhrman CR, Skolnick ML, et al. Pseudoaneurysms complicating organ transplantation: roles of CT, duplex sonography and angiography. Radiology 1988; 169: 65-70.

10 Stanley JC, Wakefield TW, Graham LM, Whitehouse WM Zelenock GB, Lindenauer SM. Clinical importance and management of splanchnic artery aneurysms. 7 Vasc Surg 1986; 3: 836-40.

11 Frey CF, Stanley JC, Eckhauser F. Hemorrhage. In: Bradley EL, ed. Complications of pancreatitis: medical and surgical EL, ed. Complications of pancreatitis: medical and

12 Hall RI, Lavelle MI, Venables CW. Chronic pancreatitis as a cause of gastrointestinal bleeding. Gut 1982; 23: 250-5.

13 Harper PC, Gamelli RL, Kaye MD. Recurrent hemorrhage into the pancreatic duct from a splenic artery aneurysm. Gastroenterology 1984; 87: 417-20.

14 Bretagne JF, Heresbach D, Darnault P, Raoul JL, Gosselin $M$, Carsin M, et al. Pseudoaneurysms and bleeding pseudo cysts in chronic pancreatitis: radiological findings and contribution to diagnosis in 8 cases. Gastrointest Radiol 1990, 15: 9-16.

15 Larson PA, Lipchik EO, Adams MB. Development and regression of visceral artery aneurysms following liver transplantation: case report. Cardiovasc Intervent Radiol 1988; 11: 75-8.

16 Busuttil RW, Brin BJ. The diagnosis and management of visceral artery aneurysms. Surgery 1980; 88: 619-24.

17 Bosch J, Kravetz D, Mastai R, Navasa M, Silva G, Chesta J, et al. Effects of somatostatin in patients with portal hyperten sion. Horm Res 1988; 29: 99-102.

18 Burroughs AK, McCormick PA, Hughes MD, Sprengers D D'Heygere F, McIntyre N. Randomized, double-blind, placebo-controlled trial of somatostatin for variceal bleeding. Gastroenterology 1990; 99: 1388-95.

19 Giugliano D, Coppola L, Misso L, Tirelli A, Passariello N, D'Onofrio F. Further studies of the significance of circulating platelet aggregates induced by somatostatin in man. Metabolism 1981; 30: 172-5. 